\title{
Classification and Premedication of Uncooperative Children
}

\author{
S. ŞIMŞ̇EK ${ }^{1}$, S. AKYÜZ ${ }^{2}$, G. ŞENER ${ }^{1}$, \\ K. GÖKER ${ }^{3}$ and Ö. GÜVENER ${ }^{3}$
}

(Received 18 January and accepted 29 October 1992)

Key words: diazepam, acepromazine, anxiety, Benton test

\begin{abstract}
Forty-three uncooperative children ranging in age from 4-12 yr were pretreated with diazepam, acepromazine or a placebo, depending on their anxiety situations.

The results showed that diazepam has a significantly more powerful effect on the successful termination of the dental procedure and on encouraging the cooperation and compliance of patients than acepromazine or placebo. The placebo was also found to be effective for increasing the cooperation of patients with negative anxiety. No significant difference was established between the actions of premedicants on pain reaction and amnesia. In the light of the present findings, it is suggested that drugs with sedative and also anxiolytic effects will be more beneficial for increasing the cooperation of children with mild or high anxiety than drugs with a sedative effect alone.
\end{abstract}

\section{Introduction}

A number of studies have been carried out since 1933 to increase the cooperation and reduce the disruptive behavior of uncooperative children during dental treatment. It has been suggested that multiple factors in a child's background cause such negative behavior. These include past medical and dental history, maternal anxiety, education and personality ${ }^{[1-5]}$. A number of approaches for the classification and management of these children have been suggested from a psychiatric or psychological viewpoint, such as familiarization, video or observation window techniques, tell-show-do, the Trieger test, desensitization, digit symbol substitution test and differential reinforcement of other behavior ${ }^{[1,3,4,6]}$. However, in most of these studies, the approach was to define the apprehension of the child and to measure his/her response to painful $\operatorname{stimuli}^{[5,7,8]}$. Moreover, it has been difficult to apply these techniques routinely, because the studies were carried out by special teams. Nevertheless, on many occasions, a physiological approach and behavioral management augmented with a drug or drug combinations, relieve fear and apprehension successfully. The variety and combined use of premedicating agents have increased the risk of adverse and toxic effects ${ }^{[7,9,10]}$. For this reason, intensive studies have been carried out in recent years. Particularly, there have been large-scale studies carried out by the American Society of Dentistry for Children (ASDC) and the Fédération Dentaire Internationale (FDI) in order to determine the ideal premedication agents and their undesirable toxic effects $^{[9,11]}$. The ASDC sent questionnaires to 6,397 dentists in order to determine the incidence of usage of sedative premedications and analgesics in the United States of America, and reported the responses it received from 2,911 dentists. These outlined the single and combined use of premedications and their variations according to geographical regions. Later, in 1989, the FDI

1 Department of Pharmacology, Faculty of Dentistry, Marmara University, Istanbul, Turkey.

2 Department of Pedodontics, Faculty of Dentistry, Marmara University, Istanbul, Turkey.

3 Department of Oral Surgery, Faculty of Dentistry, Marmara University, Istanbul, Turkey.

To whom all correspondence should be addressed: Doç. Dr. Şükran ŞIMŞEK, Marmara Üniversitesi, Diş Hekimliği

Fakültesi, Büyükçiftlik Sok. No. 6, Nişantaşi, 80200, Istanbul, TURKEY. 
published a technical report including a list of premedicating agents which can be used reliably in dentistry. In a report determining the aims of the World Health Organization for the year 2000, it was suggested that the DMF (Decayed Missing Filled) index in children up to 12 years of age be lowered to 3 and that the importance of dental health in children should be emphasized.

In the light of these data, we attempted to classify uncooperative children on the basis of their medical and maternal anxiety using our own classification method, to premedicate them with proper drugs, and to compare the effectiveness of these drugs.

\section{Materials and Methods}

In this study, dental apprehension originating either from previous medical and dental experience or from the family in 43 uncooperative children was determined. The age range of the patients was 4-12 years, and their weights varied from 15 to $25 \mathrm{~kg}$. For this purpose, two sets of questionnaires were prepared. Questionnaire 1 included questions to be asked of the mother, and those to be directed at the child were included in questionnaire 2 (Tables 1 and 2). According to the responses received, the medical and maternal anxieties of the children were established as shown in Tables 3 and 4. Groups to which drugs and placebo were to be administered were determined by the anxiety data. Administration of drugs and placebo according to anxiety situations ${ }^{[5,12]}$ and dosage forms are summarized in Table 5.

Children who had allergy, atopy, systemic disease or mental deficiency were excluded from the study. Parents' consent was obtained for all procedures and measurement of blood pressure and pulse rate was done before and $1 \mathrm{~h}$ after the administration of drugs. Drugs and placebo were administered orally, since this is an easy and acceptable route for children.

One hour after administration of the premedicating agents, Benton's perception and attention test was applied in order to determine whether the drugs had any influence on perception and attention or whether they caused amnesia. The test was repeated 15 days later at the earliest, and these results were considered to be control values. The test was not given to children below 6 years of age.

All of these pre-dental procedures were performed by personnel without hospital uniforms and in an environment not similar to a clinical setting. The procedures to be applied to the children consisted mainly of tooth extraction, cavity preparation and filling procedures. The children's cooperation and compliance to the instructions of the dentist in the clinic were recorded by the dentist, as shown in Table 6 . The study was performed under double-blind conditions.

Parametric data related to Benton's test were evaluated statistically by Student's $t$ test, and nonparametric data based on the dentist's observations of the child's behavior, by the chi-square test.

\section{Results}

The results of this study indicated that the effectiveness of diazepam was considerably higher and more significant than acepromazine maleate and placebo in the premedication of the positive and high-anxiety group. In this group, dental treatment was accomplished in a high proportion (80\%). The results of cooperation, compliance and permission are summarized in Tables 7, 8 and 9. In the mild anxiety group, acepromazine maleate failed to increase cooperation and other parameters, and the results were lower than the expected values by the chi-square test. In the negative maternal and medical anxiety group, placebo was found to be effective in increasing these parameters, possibly reflecting the positive reinforcing effects of placebo intake.

There was no significant difference between the goups with regard to the responses to painful stimuli (Table 10). As to the results of the Benton test which we applied in order to determine the amnestic effects of the drugs, there was no significant difference between the 
groups (Table 11).

No change was observed in the blood pressure, pulse and respiratory rates after the administration of the drugs. Moreover, no unwanted effects were observed after drug administration.

Table 1 Questionnaire 1

Dental and medical history of the child :

Number of dental visits :

History of prior visits :

Circumcision history in boys :

Does he/she have a sister/brother?

Jealousy behavior :

Enuresis nocturna :

Enuresis during dental visits or daytime :

Mother's or parent's cooperation with dentist or physician :

Did child learn fear of the dentist from his parents?

Table 2 Questionnaire 2

How do you feel now? Frightened, anxious..?

Will you allow us to carry our treatment?

Why do you refuse the treatment?

Does your parent beat or hurt you?

Punishment methods of the parent.

Do you know anything about the dental procedure that we are going to do?

Table 3 Evaluation schedule 1

Children had had bad experience in previous dental or medical visits,

Child has no sister or brother,

Child shows jealous behavior,

Child had a bad surgical or circumcision experience.

Enuresis and/or enuresis nocturna is present.

If a third (or more) of these answers were the same as in this schedule, medical anxiety was considered to be positive.

Table 4 Evaluation schedule 2

Mother or one of the persons in the family showed uncooperative behavior during dental or medical visits.

The child was made frightened of the dentist or physician by his parent.

The parent punished the child in an uncustomary manner.

If one of the answers was the same as in this schedule, maternal anxiety was considered to be positive. 
Table 5 Scale of Dentist's observations

\begin{tabular}{|c|c|c|c|c|}
\hline $\begin{array}{c}\text { Score } \\
\text { Behavior }\end{array}$ & 0 & 1 & 2 & 3 \\
\hline Permission & $\begin{array}{l}\quad \text { Aborted } \\
\text { (no treatment } \\
\text { given) }\end{array}$ & $\begin{array}{l}\text { Poor } \\
\text { (treatment } \\
\text { interrupted) }\end{array}$ & $\begin{array}{l}\quad \text { Good } \\
\text { (difficult, but all } \\
\text { treatment } \\
\text { performed) }\end{array}$ & $\begin{array}{l}\quad \text { Excellent } \\
\text { (no crying or } \\
\text { movement) }\end{array}$ \\
\hline Compliance & $\begin{array}{c}\text { Poor } \\
\text { (Behavior of th }\end{array}$ & $\begin{array}{l}\text { Mild } \\
\text { hildren in respor }\end{array}$ & $\begin{array}{l}\text { Good } \\
\text { to the dentist's dir }\end{array}$ & $\begin{array}{l}\text { Excellent } \\
\text { ection) }\end{array}$ \\
\hline Cooperation & $\begin{array}{l}\text { Definitely } \\
\text { uncooperative }\end{array}$ & Uncooperative & Cooperative & $\begin{array}{l}\text { Definitely } \\
\text { Cooperative }\end{array}$ \\
\hline Pain reaction & $\begin{array}{l}\text { Definitely } \\
\text { positive }\end{array}$ & Positive & Negative & $\begin{array}{l}\text { Definitely } \\
\text { negative }\end{array}$ \\
\hline
\end{tabular}

Table 6 Permissive Behavior of the children during dental treatment

\begin{tabular}{|l|c|c|c|c|c|}
\hline \multirow{2}{*}{$\begin{array}{l}\text { Permission } \\
\text { Groups }\end{array}$} & \multicolumn{2}{|c|}{$\begin{array}{c}\text { Poor } \\
(0-1)\end{array}$} & \multicolumn{2}{c|}{$\begin{array}{c}\text { Good } \\
(2-3)\end{array}$} & \multirow{2}{*}{$\begin{array}{c}\text { Total } \\
(\mathrm{n})\end{array}$} \\
\cline { 2 - 5 } & $\mathrm{O}^{*}$ & $\mathrm{E}^{*}$ & $\mathrm{O}$ & $\mathrm{E}$ & \\
\hline Diazepam & 4 & 5.58 & 11 & 9.42 & 15 \\
$\begin{array}{l}\text { Acepromazine } \\
\text { maleate }\end{array}$ & 9 & 5.51 & 5 & 8.79 & 14 \\
Placebo & 3 & 5.21 & 11 & 8.79 & 14 \\
\hline Chi-Square $=6.59$ & & $\mathrm{p}<0.05$ \\
\hline * Observed values (O) and Expected values (E) \\
\hline
\end{tabular}

Table 7 Pain reactions of the children during dental treatment

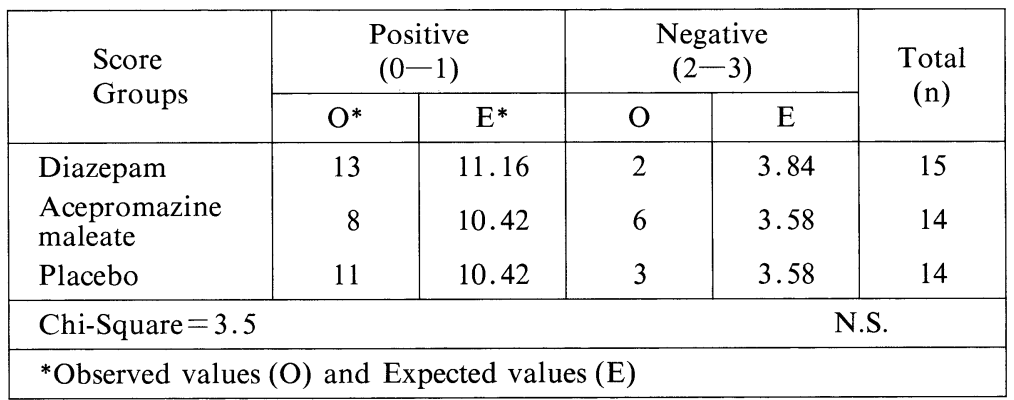


Table 8 Statistical differences of the Benton test results upon comparison of the groups (Student's $t$ test)

\begin{tabular}{|c|ccc|}
\hline $\begin{array}{c}\text { Groups } \\
\text { Benton test }\end{array}$ & D-A & D-P & A-P \\
\hline & $7.73-7.23$ & $7.73-8.67$ & $7.23-8.67$ \\
B I & $\mathrm{t}: 0.461$ & $\mathrm{t}: 0.842$ & $\mathrm{t}: 1.256$ \\
& N.S. & N.S. & N.S. \\
\hline & $9.30-7.80$ & $9.30-11.80$ & $7.80-11.80$ \\
B II & $\mathrm{t}: 1.098$ & $\mathrm{t}: 2.012$ & $\mathrm{t}: 2.116$ \\
& N.S. & N.S. & N.S. \\
\hline
\end{tabular}

D: Diazepam A : Acepromazine maleate P: Placebo

B I : Benton I test results of treated groups

BII : Benton II test results represent control values of treated groups.

N.S. : Not significant

Table 9 Permissive Behavior of the children during dental treatment

\begin{tabular}{|l|c|c|r|r|c|}
\hline \multirow{2}{*}{$\begin{array}{l}\text { Permission } \\
\text { Groups }\end{array}$} & \multicolumn{2}{|c|}{$\begin{array}{c}\text { Poor } \\
(0-1)\end{array}$} & \multicolumn{2}{c|}{$\begin{array}{c}\text { Good } \\
(2-3)\end{array}$} & $\begin{array}{c}\text { Total } \\
(\mathrm{n})\end{array}$ \\
\cline { 2 - 5 } & $\mathrm{O}^{*}$ & $\mathrm{E}^{*}$ & $\mathrm{O}$ & $\mathrm{E}$ & \\
\hline Diazepam & 4 & 5.58 & 11 & 9.42 & 15 \\
Acepromazine & 9 & 5.51 & 5 & 8.79 & 14 \\
maleate & 3 & 5.21 & 11 & 8.79 & 14 \\
Placebo & 3 & \multicolumn{4}{|c|}{$\mathrm{p}<0.05$} \\
\hline Chi-Squared =6.59 \\
\hline * Observed values (O) and Expected values (E)
\end{tabular}

Table 10 Pain reactions of the children during dental treatment

\begin{tabular}{|l|r|c|c|c|c|}
\hline \multirow{2}{*}{$\begin{array}{l}\text { Score } \\
\text { Groups }\end{array}$} & \multicolumn{2}{|c|}{$\begin{array}{c}\text { Positive } \\
(0-1)\end{array}$} & \multicolumn{2}{c|}{$\begin{array}{c}\text { Negative } \\
(2-3)\end{array}$} & \multirow{2}{*}{$\begin{array}{c}\text { Total } \\
(\mathrm{n})\end{array}$} \\
\cline { 2 - 5 } & $\mathrm{O}^{*}$ & $\mathrm{E}^{*}$ & $\mathrm{O}$ & $\mathrm{E}$ & \\
\hline Diazepam & 13 & 11.16 & 2 & 3.84 & 15 \\
Acepromazine & 8 & 10.42 & 6 & 3.58 & 14 \\
maleate & 11 & 10.42 & 3 & 3.58 & 14 \\
Placebo & \multicolumn{4}{|c|}{ N.S. } \\
\hline Chi-Squared =3.5 \\
\hline * Observed values (O) and Expected values (E)
\end{tabular}


Table 11 Statistical differences of the Benton test results upon comparison of the groups (Student's $t$ test)

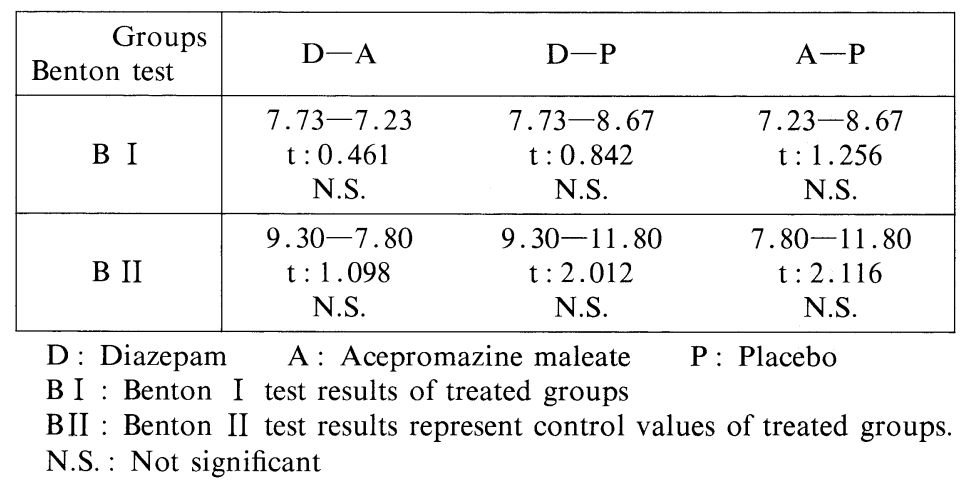

\section{Discussion}

Methods used to improve cooperation in uncooperative children during dental procedures show considerable variation. Some of them take a long time or necessitate the contribution of special teams, whereas others are age-limited or the results questionable as to whether they are double-blind or placebo-controlled. Since a homogeneous source for examination of the behavior of children cannot be found, it is considerably difficult to develop a standard method. Moreover, whether apprehension or anxiety causes uncooperative behavior in children has been a matter of debate for a long time. Controversy over the concepts of apprehension and anxiety has appeared, and has not yet been resolved.

The most frequently used method for improving cooperation is to premedicate the children with pharmacological agents. For this purpose, narcotic analgesics have been widely used in the U. S. A. However, it has been reported that combined use of these drugs with others or their use in private offices has increased the risk factors. This situation has led to legal problems ${ }^{[6,7,9,13-16]}$. In a dental practice employing general anesthetics, an increase in the number of drugs used has been suggested as another risk factor. Furthermore, this is not an advantageous form of application for short-term procedures, and also is unnecessary ${ }^{[1,6,17]}$. Chloral hydrate is among the premedicating agents adopted by the FDI, and has been widely used. Nevertheless, there have been no precise reports on its administration dosage or its best combinations with other drugs to produce a more successful outcome ${ }^{[12,18-21]}$.

In the U.S. A., it has been established that $64 \%$ of pedodontists choose premedication agents with sedative effects, $10 \%$ use various other agents, and $15 \%$ do not use any premedication $^{[7,9,10,15,17]}$. There are no statistical data on pharmacological agents chosen by dentists in Turkey.

It has been suggested that this variability might be harmful rather than beneficial, since the FDI has included only a small number of premedication agents which can be used reliably. Diazepam, a benzodiazepine derivative, and also some of the phenotiazine derivatives, can be used for this purpose reliably ${ }^{[22-24]}$.

In this study, diazepam was used alone and in a single dose. It increased the cooperation and improved the regressive behavior of the children whose level of anxiety was assumed to be the highest. It may be suggested that the effectiveness of diazepam arises from its anxiolytic effect, since acepromazine, which also has a sedative effect, has no anxiolytic action, and has been found ineffective for improving the behavioral parameters of children with mild anxiety. It is of interest that a successful result was obtained in the placebo group. The effectiveness of placebo on children with negative medical and maternal anxiety can be explained by the absence of examined anxieties and also the positive reinforcing effects of placebo intake. Moreover, the 
durability of the improvement in cooperation should also be evaluated by systemic withdrawal of treatment during follow-up appointments.

It was found that the drugs used in this study had no amnestic effects. It may be suggested that the effects of diazepam in behavioral management are not related to amnesia. In fact, it has been reported that diazepam, given in a single dose, does not produce amnesia ${ }^{[2,25]}$.

Because neither diazepam nor acepromazine has an analgesic effect, the reactions to painful stimuli were found not to differ from those in the placebo group. Those children who show pain reactions are those who exhibit difficulty in cooperation even after drug administration and, probably, their pain response originates from this cooperation difficulty. In the acepromazine group, $57.1 \%$ of the children showed a pain reaction, reflecting the unsuccessful effects of the drug in increasing cooperation. In the diazepam and placebo groups, the ratios were $86.6 \%$ and $78.6 \%$, respectively, reflecting successful management of noncooperation.

No adverse effect was observed with the drugs administered in our study. It has also been reported that no unwanted effects are produced by single-dose administration of these drugs ${ }^{[8,24]}$.

In this study, fear of dentist has been overcome in poorly cooperated children. Moreover, children who have been cooperated by diazepam or placebo and their parents asked to have medication in their second visit. EL BADRAWY AND RIEKMAN ${ }^{[13]}$ have established a positive relationship between the parent's anxiety and the child's behavior in a dental situation. It is true that the parent who is emotionally upset may not be able to support and comfort his/her child before and after dental treatment ${ }^{[1]}$.

In the light of the presented study, 120 children were treated in the same manner successfully (unpublished data).

\section{Conclusion}

In conclusion, according to this classification method, children with mild or high anxiety should be treated with diazepam or other anxiolytic agents. This method can also be used in the separation of the negative anxiety group which is influenced by placebo.

No side effects including nausea, vomiting, amnesia, changes in blood pressure or pulse rate were observed after administrating a single dose of drug and placebo.

\section{References}

[1] Camm, J. H., Mourino, A. P., Cobb, E. J. and Doyle, T. E.: Behavioral changes of children undergoing dental treatment using sedation versus general anesthesia, Pediat. Dent., 9, 111-117, 1987

[2] Clark, M. S., Silverstone, L. M., Coke, J. M. and Hicks, J.: Midazolam, diazepam, and placebo intake as intravenous sedatives for dental surgery, Oral Surg. Oral Med. Oral Pathol., 63, 127-131, 1987

[3] Gordon, D. A., Terdal, L. and Sterling, E.: The use of modelling and desensitization in the treatment of phobic child patient, J. Dent. Child., March-Apr., 102-105, 1974

[4] Masek, B. J., Canion, S. B., Cataldo, M. F., Riordan, M. M. and Boe, R. B.: Behavioral procedures to increase cooperation of developmentally disabled children with dental treatment, Pediat. Dent., 4, 317-321, 1982

[5] WRIGHT, G. Z.: Behavior Management in Dentistry for Children, 56-72, W. B. Saunders Co., Philadelphia, 1975

[6] Brandt, S. K. and Bugg, L.: Problems of medication with the pediatric patient, Dent. Clin. North Am., 28 $563-579,1984$

[7] Goodson, J. M. and Moore, P. A.: Life-threatening reactions after pedodontic sedation: an assessment of narcotic local anesthetic and antiemetic drug interaction, $J A D A, \mathbf{1 0 7}, 238-245,1983$

[8] Trevor, A. J. and Wey, W. L.: Sedative-hypnotics. In: Basic and Clinical Pharmacology, 2nd ed., Katzung, B. G. ed., 247-257, Lange Medical Publ., Calif., 1984

[9] Aubuchon, R. W.: Sedation liabilities in pedodontics, Pediat. Dent., 4, 171-180, 1982

[10] Weinstein, P., Domot, P. K. and Holleman, E.: The use of nitrous oxide in the treatment of children, $J A D A$, 112, 325-331, 1986

[11] Fédération Dentaire Internationale Technical Report No. 32: Premedication in dentistry, Int. Dent. J., 39, 5561, 1989

[12] Houpt, M. I., Sheskin, R. B., Koenigsberg, S. R., Desjardins, P. J. and Shey, Z.: Assessing chloral hydrate 
dosage for young children, J. Dent. Child., Sep.-Oct., 364-369, 1985

[13] El Badrawy. H. E. and Riekman, G. A.: A survey of parental attitudes toward sedation of their child, Pediat. Dent., 8, 206-208, 1986

[14] Lambert, L. A., Nazif, M. M., Moore, P. A. and Zullo, T. G.: Nonlinear dose-response characteristics of alphaprodine sedation in preschool children, Pediat. Dent., 10, 30-33, 1988

[15] Needleman, H. L.: Conscious sedation for pediatric outpatient dental procedures, Int. Anesth. Clin., 27, 102-107, 1989

[16] Tobias, M. G., Lispschultz, D. H. and Album, M. M.: A study of three preoperative sedative combinations, J. Dent. Child., Nov.-Dec., 453-459, 1975

[17] Enger, D. J. and Mourino, A. P.: A survey of 200 pediatric dental general anesthesia cases, J. Dent. Child., Jan.-Feb., 36-41, 1985

[18] Evans, W. O., Tannenbaum, K., Turek, B. and Alling, E. F.: A method for evaluating the use of premedicating agents in difficult pedodontic patients, J. Dent. Child., Sep., 317-323, 1966

[19] Houpt, M. I., Koenigsberg, S. R., Weiss, N. J. and Desjardins, P. J.: Comparison of chloral hydrate with and without promethazine in the sedation of young children, Pediat. Dent., 7, 41-46, 1985

[20] Moody, E. H., Mourino, A. P. and Campbell, R. I.: The therapeutic effectiveness of nitrous oxide and chloral hydrate administered orally, rectally, and combined with hydroxyzine for pediatric dentistry, J. Dent. Child., Nov.-Dec., 425-429, 1986

[21] RoBbins, M. B.: Chloral hydrate and promethazine as premedicants for the apprehensive child, J. Dent. Child., Sep., 327-331, 1967

[22] Auil, B., Cornejo, G. and Gallardo, F.: Flunitrazepam and diazepam compared as sedatives in children, J. Dent. Child., Jan.-Feb., 442-444, 1983

[23] Smith, T. C., Cooperman, L. H. and Wolman, H.: History and principles of anaesthesiology. In: The pharmacological Basis of Therapeutics, 6th ed., eds. Gilman, A. G., Goodman, L. S. and Gilman, A. G., 258-275, MacMillan Publ. Co., New York, 1980

[24] Tolksdorf, W., Gerlach, C., Hartung, M. and Heltenbach, A.: Midazolam and pethidine/promethazine for intramuscular premedication, Anaesthesiology, 36, 275-279, 1987

[25] Barclay, J. K., Mac, D., Hunter, K. and McMillan, W.: Midazolam and diazepam compared as sedatives for outpatient surgery under local analgesia, Oral Surg. Oral Med. Oral Pathol., 59, 349-355, 1985 